\title{
EL JORDÁN QUE HA DE PURIFICARNOS: LA REFORMA EDUCATIVA DE GERMÁN GAMAZO EN 1898*
}

\author{
Ángel González de Pablo \\ Unidad de Historia de la Medicina - Facultad de Medicina - U.C.M. Madrid (España)
}

\section{RESUMEN}

La derrota colonial del verano de 1898 desató un enorme afán de renovación pedagógica en la opinión pública española, al ser consideradas las deficiencias en este campo una de las causas esenciales del Desastre. El entonces ministro de Fomento, Germán Gamazo, recogió esa demanda y emprendió, en septiembre de ese año, una precipitada reforma mediante una serie de reales decretos que adolecían de numerosas incoherencias. A pesar de ello, su acogida fue en un principio, debido a ese anhelo de regeneración de que estaba saturado el ambiente social, muy favorable. Sólo en la primera semana de octubre, las críticas, hasta entonces puntuales, comenzaron a generalizarse, tornándose todavía más acerbas cuando, a partir de la tercera semana, se comenzaron a publicar algunas de las corruptelas que acompañaban a la reforma supuestamente regeneradora de la nación. Todo lo cual condujo a la dimisión de Gamazo a finales de ese mes y dio al traste con todas sus disposiciones poco después.

Este trabajo analiza las diversas motivaciones de la reforma gamacista, su recepción en los distintos medios periodísticos (profesionales, políticos, partidistas e independientes), las causas de su descalabro y las consecuencias que se extrajeron de ese fracaso.

\section{SUMMARY}

The colonial defeat in the summer of 1898 unleashed a strong urge for deep educational changes in Spanish public opinion, as the shortages in this field were considered one of essential causes of the Disaster. Germán Gamazo, the Developement minister at that time, undertook this demand and promulgated several hasty decrees riddled with deficiencies in September and October of that year. Nevertheless, the response to them was at first very favourable due to the yearning for regeneration that existed in the Spanish society. Only from the first week of October onwards did criticisms, until then very limited, increase considerably, becoming even severer in the third week when

* Este trabajo ha sido realizado dentro del proyecto de la DGES PB-96-0631-C03-01. Una primera versión del mismo se presentó como comunicación al XI Congreso Nacional de Historia de la Medicina, celebrado en Santiago de Compostela en septiembre de 1998. 


\section{ÁNGEL GONZÁLEZ DE PABLO}

several cases of corruption, which stained the reform, were published.That situation finally led Gamazo to resign at the end of that month and wrecked his reform shortly after.

This paper analyses the various motives behind Gamazo's reform, its reception in the diverse types of press (professional, political, conservative, liberal or independent), the reasons for its lack of success and the consequences that resulted from this failure.

\section{INTRODUCCIÓN}

A lo largo de la Restauración, la educación, en todos sus niveles, estuvo sujeta a numerosos avatares ${ }^{1}$. Su reforma en profundidad fue solicitada durante todo este período por los intelectuales pertenecientes o afines a la Institución Libre de Enseñanza ${ }^{2}$, aunque hubo que esperar a la llegada de Luis Albareda al ministerio de Fo-

1 Sobre la historia de la educación en España durante este período, véanse: TURIN, I. (1967), La educación y escuela en España de 1874 a 1902. Liberalismo y tradición, trad. de la ed. fr. [1963] por J. Hernández Alonso, Madrid, Aguilar; y PuElles BeníteZ, M. de (1980), Educación e ideología en la España contemporánea, Barcelona, Labor. Asimismo, resultan útiles los textos y documentos seccionados por M. de Puelles Benítez en el tomo III de la Historia de la educación en España. (De la Restauración a la II República), Madrid, Ministerio de Educación y Ciencia, 1982. Para los últimos años de esta época, consúltese: DELGADO CRIADO, B. (1997), «La generación del 98 y la educación española», $R e$ vista de Educación, núm. Extra, 11-31. En relación con la educación universitaria, véanse: PESET, M.; PESET, J. L. (1992), «Las universidades españolas del siglo XIX y las ciencias», Ayer, 7, 19-49; y GóMEZ GARCÍA, M. ${ }^{a}$ N. (1997), «La Universidad española del 98 al 23: pensamiento, legislación, prensa», $R e$ vista de Educación, núm. Extra, 115-135. Para la enseñanza de la medicina en estos años sigue aportando datos de interés: GARCíA DEL CARrizo, M. ${ }^{a}$ G. (1963), Historia de la Facultad de Medicina de Madrid, Madrid, tesis doctoral inédita, UCM.

2 Para una visión general de las ideas de los institucionistas sobre la reforma educativa, resultan muy provechosos: Cossío, M. B. (1929), De su jornada (fragmentos), Madrid, Imprenta de Blass; y las antologías dedicadas a Giner y a Cossío: Antología pedagógica de Francisco Giner de los Ríos, selecc. de Fr. J. Laporta, Madrid, Santillana, 1977; GINER DE LOS Ríos, Fr. (1990), Escritos sobre la Universidad española, ed. de T. Rodríguez Lecea, Madrid, Espasa-Calpe; y Cossío, M.B. (1985), Una antología pedagógica, selección de textos, presentación y bibliografía de J. Carbonell Sebarroja, Madrid, Ministerio de Educación y Ciencia.

Entre la considerable bibliografía sobre la I.L.E. y la llamada «institución difusa», una información panorámica sobre sus iniciativas para la renovación educativa puede obtenerse de: GóMEZ MOLLEDA, M. ${ }^{a}$ D. (1981), Los reformadores de la España contemporánea [1 ${ }^{\mathrm{a}}$ ed. 1966], Madrid, C.S.I.C.; ABELláN, J. L. (1989), Historia crítica del pensamiento español, tomo V (I) [La crisis contemporánea], Madrid, Espasa-Calpe, pp. 146-174; CACHO VIU, V. (1962), La Institución Libre de Enseñanza, I [Orígenes y etapa universitaria], Madrid, Rial; JIMÉNEZ-LANDI, A. (1996), La Institución Libre de Enseñanza y su ambiente, tomo III [Periodo escolar 1881-1907], Madrid, Ministerio de Educación y Cultura, pp. 123-190 y 375-425; y TURIN (1967), pp. 199-220. Para la percepción de los institucionistas de la crisis del 98, véase el reciente trabajo de: LAPORTA, Fr. L. (1998), «La Institución Libre de Enseñanza y la generación del 98”, en: Tiempos del 98, Sevilla, A. Pinelo, 77-98.

No debe pasarse por alto que las recomendaciones propugnadas por los diversos miembros y simpatizantes de la I.L.E. no siempre fueron coincidentes. A modo de ejemplo, puede mencionarse que Una- 
mento con el gobierno liberal en 1881, y a la celebración del primer Congreso Nacional Pedagógico en 1882, para que empezaran a advertirse los primeros influjos de la I.L.E. en la política pedagógica del país ${ }^{3}$. Pero, a pesar de que desde ese año de 1881 no son pocos los ministros de Fomento y los directores de Instrucción Pública que son institucionistas o tienen relaciones ideológicas o afectivas con la Institución ${ }^{4}$, las propuestas renovadoras de ella emanadas alcanzaron contados reflejos legales, no pasando de ser en la mayoría de los casos, meros rellenos efectistas de discursos políticos o artículos periodísticos ${ }^{5}$. Este estado de cosas explica que, al comenzar el 98, hubiera un sentimiento muy extendido en relación con que los aislados cambios pedagógicos legales operados en la última década no sólo no habían conducido a ningún resultado positivo, sino que habían dado lugar incluso a que la educación del país se fuera deteriorando todavía más, en concordancia con el retroceso producido simultáneamente en otros ámbitos, como era el caso de la producción intelectual, científica o industrial 6 .

Con estos antecedentes, el Desastre del 98 actuó en el terreno de lo educativo, de igual manera que en tantos otros, como un revulsivo. Las carencias educacionales se vieron muy dramáticamente en la opinión pública - harta de que no acabaran de solucionarse nunca - como una de las causas fundamentales del marasmo patrio; y la reforma pedagógica se convirtió en una reivindicación popular de primera magnitud. Las tesis de los institucionistas recibieron nuevos bríos, trascendieron el marco de los expertos y pasaron al dominio del pueblo común, saturándose el ambiente social de anhelos pedagógicos.

Esta preocupación por la mejora educacional se vio además reforzada por el parecido entre la situación de esta España de 1898 y la Francia de 1870, el cual, como los periódicos pusieron de relieve $e^{7}$, resultaba evidente y aleccionador ${ }^{8}$. En la Francia de

muno coincidía con Giner en la negación de una universidad profesionalizante y burocratizada, pero no compartía su defensa de la autonomía universitaria. Sobre el pensamiento unamuniano en torno a los diferentes problemas educativos, véanse: DELGADO CRIADO, B. (1973), Unamuno educador, Madrid, Editorial Magisterio Español; GómeZ MolledA (1981), pp. 385-416; y GóMEZ MolledA, M. ${ }^{a}$ D. (1997), «Unamuno, rector “regeneracionista”», Revista de Educación, núm. Extra, 137-147.

3 GÓMEZ MOLlEDA (1981), pp. 442-445.

4 Una relación de los mismos puede verse en: GÓMEZ MOLLEDA (1981), p. 424.

5 Delgado CRIADO (1997), p. 16.

6 En el primer número de año 1898 de El Siglo Médico podía leerse el siguiente párrafo: «intelectual, científica y profesionalmente considerados seguimos siendo, por mal de nuestros pecados, un pueblo inferior, que no sale de su atraso en la producción, que no vigoriza y desarrolla su vida intelectual, y que más bien empeora que mejora sus costumbres, su educación, su disciplina y los elementos todos que constituyen la base de su existencia y la razón de su mérito». CARLÁN, D. "Año de 1898", El Siglo Médico, 2 de enero de 1898, 1-2; p. 1. Este y otros párrafos del artículo de similar cariz se reprodujeron en $L a$ Farmacia Española: «Crónicas. Nota pesimista», La Farmacia Española, 13 de enero de 1898, p. 25.

7 Cfr., por ejemplo: «Reformas en la enseñanza. De espaldas a la realidad», El Imparcial, 14 de mayo de 1899; y «La reconstitución del país», La Época, 14 de septiembre de 1898. 


\section{ÁNGEL GONZÁLEZ DE PABLO}

la Débâcle, la superioridad militar alemana y la consiguiente derrota ante sus armas se atribuyó, del mismo modo que se haría casi tres décadas después en la España del Desastre, a la mayor consistencia de la ciencia y de la docencia de los enemigos. La toma de conciencia por parte de la Francia de Sedan de las causas de una derrota tan humillante dio lugar a que la naciente III República hiciera de la mejora de la Universidad (siguiendo en ello el modelo de las universidades alemanas), así como de la extensión a toda la población de los primeros grados de la enseñanza, uno de sus objetivos prioritarios 9 . Los esfuerzos en esta dirección, unidos a una serie de cambios en el panorama socio-político, acabaron provocando una reacción muy saludable de la sociedad francesa, la cual tuvo uno de sus exponentes más llamativos en la Exposición Universal de París celebrada en $1900^{10}$.

Pues bien, la lección que ofrecía el caso francés y la fiebre pedagógica que se desató desde mediados de agosto del 98 hicieron que se incrementara drásticamente la presión popular para que se produjera de una vez una auténtica transcripción legal de las exhortaciones institucionistas. Como resultado de esta exigencia, se emprendió una compleja tarea legislativa, la cual a la postre se acabaría prolongando durante un largo lapso temporal que abarcaría las primeras décadas del siglo XX. El comienzo de la misma puede dividirse en dos momentos. El primero, encarnado por el entonces ministro de Fomento Germán Gamazo (1838-1901) y al cual va a estar dedicado el presente trabajo, se malogró rápidamente por la excesiva precipitación y la búsqueda de rápidos resultados. Tan sólo con el segundo, que tomó carta de naturaleza a partir de 1900 con la llegada de García Alix primero y del conde de Romanones después al ministerio de Instrucción Pública, las disposiciones, al recoger de una forma más completa y coherente las directrices institucionistas ${ }^{11}$, alcanzarían un cierto arraigo.

8 En relación con los distintos perfiles de esta semejanza, más aparente que real, véase: CACHO VIU, V. (1997), «Francia 1870-España 1898", en: V. Cacho Viu, Repensar el 98, Madrid, Biblioteca Nueva, pp. 77-115. Este trabajo ha aparecido también en la Revista de Occidente, en su n ${ }^{\circ} 202-203$, de marzo de 1998

9 Sobre la historia de la educación en Francia en esta época, puede consultarse: LIARD, L. (18881894), L'enseignement superieur en France (1789-1889), 2 vols., París, A. Colin; PONTEIL, F. (1966), Histoire de l'enseignement en France. Les grandes étapes 1789-1964, París, Sirey; PROST, A. (1986), Histoire de l'enseignement en France, 1800-1967 [1 $1^{\text {a }}$ ed. 1967], París, A. Colin; y WEISZ, G. (1983), The Emergence of Modern Universities in France 1863-1914, Princeton, Princeton U. P.

10 A este respecto, la Pardo Bazán no dejo de señalar, en el último artículo de la serie que publicó en El Imparcial sobre la Exposición Universal de 1900, la hiriente diferencia entre el brillante balance francés y el pobre español, para hacer ver la necesidad de seguir los pasos de nuestro vecino si se quería conseguir la regeneración del país: PARDO BAZÁN, E., «En la Exposición: balance», El Imparcial, 3 de diciembre de 1900

11 Sobre la influencia francesa en las reformas defendidas por los institucionistas, veánse: BARATAS DíEZ, L. A. (1995), «La influencia francesa en el proyecto de reforma universitario español de principios del siglo XX: una analogía incompleta», Hispania, 55/2, 645-672; y BARATAS DíEZ, L. A. (1997), Introducción y desarrollo de la biología experimental en España entre 1868 y 1936, Madrid, C.S.I.C., pp. 101-110. 


\section{EL JORDÁN QUE HA DE PURIFICARNOS: LA REFORMA EDUCATIVA DE GERMÁN GAMAZO}

\section{GAMAZO Y EL ARREBATO PEDAGÓGICO DEL 98}

La pérdida de valor de la peseta a causa de la guerra había originado, ya a primeros de 1898, un considerable aumento del precio de la harina y del pan. El malestar por la carestía del pan se incrementó, además, por la subida del impuesto sumamente impopular que gravaba los bienes de primera necesidad: el odiado impuesto de consumos sobre la comida, los combustibles y las bebidas. En este estado de profundo descontento social, el primer motín, de los numerosos y violentos que a partir de mayo del 98 se multiplicarían por la geografía del país ${ }^{12}$, se desencadenó en Gijón el día 2 de este mes, un día después de la derrota de Cavite. El 3 de mayo comenzó en Cáceres un nuevo motín a causa del pan y a partir de aquí los disturbios, avivados por el espíritu patriótico zaherido tras la derrota de la flota española, se extendieron por todo el estado. El gobierno, en el poder desde el 4 de octubre de 1897, decretó la ley marcial (la cual el día 11 afectaba a todas las provincias con la sola excepción de Álava), pero no pudo impedir con ello la crisis, que tuvo lugar el día 9. Moret, ministro de Ultramar y principal cabeza de turco de la situación, se vio forzado a dimitir, arrastrando en su caída a otros miembros del gabinete liberal ${ }^{13}$.

Sagasta intentó entonces que Germán $\mathrm{Gamazo}^{14}$, uno de los principales prohombres del partido, entrara a formar parte del gobierno, pues el apoyo de los gamacistas, al quedar los moretistas fuera de él, resultaba en aquellas circunstancias imprescindible para dotarlo de una cierta estabilidad. Los gamacistas eran rivales de los moretistas y estaban aliados con los monteristas de Montero Ríos ${ }^{15}$. Sagasta sabía

12 Una breve descripción de los motines de mayo del 98 puede verse en BALFOUR, S. (1997), El fin del imperio español (1898-1923), trad. de la ed. ingl. [1997] de A. Desmonts, Barcelona, Crítica, pp. 112117. Para contemplar el reflejo en la prensa de aquellos incidentes día a día, cfr.: FIGUERO, J.; SANTA Cecilia, C. (1997), La España del Desastre, Barcelona, Plaza \& Janés, pp. 173-184. Para un conocimiento más detallado de estos «conflictos del hambre», consúltense: ARRIERO, Mª L. (1984), «Los motines de subsistencias en España, 1895-1905", Estudios de Historia Social, 30, 193-250; y CASTRO ALFín, D. (1991), «Protesta popular y orden público: los motines de consumo», en: J. L. García Delgado (ed.), España entre dos siglos (1875-1931). Continuidad y cambio, Madrid, Siglo XXI, 109-123.

13 «La crisis», El Globo, 17 de mayo de 1898.

14 Gamazo, el barón del trigo castellano y cacique liberal, convirtió prácticamente la totalidad de Castilla la Vieja en feudo suyo a través de la poderosa Liga agraria que gobernaba la producción y el comercio del trigo. Fue cuatro veces ministro y las cuatro con Sagasta. La primera vez (1883) de Fomento, la segunda (1886) de Ultramar, la tercera (1892) de Hacienda y la cuarta (1898) nuevamente de Fomento.

15 Tanto el partido conservador como el liberal eran «partidos de notables». No integraban en sus filas -ni tampoco lo buscaban- a las masas, sino a un reducido número de personajes con una capacidad de influencia personal. Sus rivalidades y tensiones tenían una base personalista y las facciones recibían el nombre del dirigente que las encabezaba. Sobre las características de estos partidos y del sistema electoral de la España finisecular, véanse: DARDÉ, C. (1997), «La vida política: elecciones y partidos», en: J. P. Fusi; A. Niño (eds.), Vísperas del 98. Orígenes y antecedentes de la crisis del 98, Madrid, Biblioteca Nueva, 64-74; y ÁlVAREZ JuNCO, J. (1997), «Estado y sociedad durante la década de 1890", en J. P. 


\section{ÁNGEL GONZÁLEZ DE PABLO}

además que, si Gamazo accedía al gobierno, los monteristas pondrían el grito en el cielo y se sentirían traicionados, lo cual quebrantaría las relaciones entre Gamazo y Montero Ríos y le dejaría a él más margen de maniobra en unos momentos políticos muy delicados. Tras algunas reticencias derivadas de este estado de cosas, que dilataron una semana la formación del nuevo gabinete ${ }^{16}$, Gamazo, so pena de acarrear la culpa de la caída de los liberales, aceptó finalmente la propuesta, distanciándose con ello de Montero Ríos. Pero estableció la condición de mantenerse con una cierta independencia dentro del gobierno, al objeto de no aparecer como un mero continuador de la administración anterior moretista y poder desligarse de cualquier tipo de responsabilidad derivada de los resultados de una gestión, no precisamente exitosa ${ }^{17}$. Exigió, así, a lo que parece, no desempeñar las carteras de Ultramar, Estado, Gobernación ni Hacienda (las mas quemadas por la crisis), pidiendo un ministerio secundario en aquellos momentos dominados por la urgencia de la guerra, como eran el de Gracia y Justicia o el de Fomento (que comprendía Obras Públicas e Instrucción Pública), decantándose finalmente por este último. ${ }^{18}$ Sin embargo, pese a ocupar un aparente segundo plano en el nuevo gobierno, Gamazo, como empezó a salir a la luz años más tarde, desempeñó, desde la sombra, un papel determinante en todas las resoluciones importantes de aquel gabinete, entre ellas las que condujeron al Protocolo de paz de Washington del 12 de agosto ${ }^{19}$.

Fue tras la firma del Protocolo de paz cuando se produjo la situación adecuada para que su actuación política dejara de ser, como había sido desde mayo a agosto, oscura y callada, y se convirtiera en abierta y rentable de cara a atraerse el favor de la opinión pública. Circunstancia propicia se fraguó, como se ha señalado en el apartado previo, merced al arrebato pedagógico que desató la derrota colonial. Los españoles del Desastre, con una cierta semejanza a lo ocurrido en la Francia de l'année térrible, pensaron entonces que el remedio de los males de la patria radicaba en la escuela. El pensamiento no era en sí mismo, claro es, nuevo. Lo novedoso consistía en que nunca hasta entonces se había pronunciado con tanta intensidad, por tanta gente y en tan variados foros. La preocupación pedagógica pasó en esos momentos del mundo intelectual al pueblo común; se propagó de las cátedras y ateneos a las

Fusi; A. Niño (eds.), Vísperas del 98. Orígenes y antecedentes de la crisis del 98, Madrid, Biblioteca Nueva, 47-64, pp. 59-61.

16 Estas dubitaciones fueron resaltadas por la prensa menos proclive a Sagasta: «La crisis», La Época, 17 de mayo de 1898; y «El nuevo gobierno», El Tiempo, 18 de mayo de 1898. Y, a su vez, minimizadas por la más afín: «Sobre la crisis», El Correo, 18 de mayo de 1898.

17 Cfr.: «La primera impresión», El Imparcial, 19 de mayo de 1898; «El día de ayer. La crisis», El Liberal, 18 de mayo de 1898; y «El nuevo gobierno», Heraldo de Madrid, 18 de mayo de 1898.

18 «La crisis», El Imparcial, 18 de mayo de 1898.

19 «D. Germán Gamazo», Heraldo de Madrid, 22 de noviembre de 1901. 
columnas de los periódicos y de las revistas, a las tertulias y a la calle ${ }^{20}$. Se generó, de esta manera, un clima de opinión, perceptible ya claramente en la segunda mitad de agosto y primeros días de septiembre ${ }^{21}$, que ligaba visceral y vehementemente la regeneración del marasmo nacional a la reforma educativa, «el Jordán que ha de purificarnos» según la efectista frase del entonces ex-director de Instrucción Pública, Eduardo Vincenti, que alcanzó una cierta popularidad en aquellos momentos ${ }^{22}$.

La reorganización de la educación, convertida en panacea de todos los males, pasó a ser, así, una prioridad política; lo que originó que, desde los primeros días de septiembre, el ministerio de Fomento dejara el papel secundario en el que había permanecido en los meses anteriores y adquiriera un puesto preponderante en la actualidad nacional. Y, consecuentemente, Gamazo fue requerido para encabezar la puesta en marcha de la regeneración del país: «Montero Ríos, Vincenti y Gamazo, tienen en su mano - proclamaba el semanario jurídico La Ley - la regeneración de esta España tan corrompida, peleen contra los caciquismos hasta su completo exterminio y hagan educación verdad, desde la escuela de abecedarios a las más superiores» ${ }^{23}$.

Gamazo no era ajeno a las ideas de los institucionistas ${ }^{24}$. En su anterior etapa al frente del ministerio de Fomento, al cual había accedido en 1883 sucediendo a Albareda, había realizado tentativas, aunque sin mucho éxito, de atribuir al Estado el pago de los maestros, consiguiendo al menos, como había recomendado el Congreso Na-

20 Sobre el furor pedagógico de esos momentos, cfr.: PUELles BENíteZ (1980), pp. 237-244; GÓMEZ MOLLEDA (1981), pp. 370-371; GóMEZ MOLLEDA (1997), p. 137; y DIEGO, E. de (1997), «¿1898 como inicio de una nueva orientación de la política española?», en: J. Velarde Fuentes (coord.), Perspectivas del 98. Un siglo después, Ávila, Junta de Castilla y León, 61-79; pp. 63-65.

21 Para valorar el tono marcadamente emocional que alcanzó esta demanda de reforma educativa como impulso para la regeneración nacional en la prensa política y en la profesional durante aquel verano, $f f r:$ : FRAIMÓN, «La educación nacional». Heraldo de Madrid, 11 de septiembre de 1898; CARLÁN, D., «Algo de patología nacional», El Siglo Médico, 21 de agosto de 1988, pp. 529-532; y SÁNCHEZ y RUBIO, E., «Algo sobre patología nacional española», El Siglo Médico, 28 de agosto de 1898, pp. 548-549.

A partir de octubre, las peticiones de cambios en la educación no tendrán los tintes tan melodramáticos que habían tenido en agosto y septiembre y que la convertían en el remedio de todos los males (frases como la del artículo arriba citado de Sánchez y Rubio «no es, por tanto, ni Don Juan ni Don Pedro quien ha de curar a España. Es Don Maestro de escuela y Compañía», que -con diversas formas- tan frecuentemente aparecieron por entonces, se verán con mucha menos asiduidad de octubre en adelante). Eso no implica que los artículos dedicados a la regeneración nacional aparecidos desde esta fecha no dejaran de reclamar una drástica mejora educativa, sino que ésta pasó a contemplarse, más razonablemente, en el contexto de una serie de cambios en la estructura social, política y económica que debían acompañarla para hacerla posible y verdaderamente fructífera. Cfr.: CLARín, «Los futuros: Don Leopoldo Alas», $E l$ Globo, 12 de octubre de 1898; RAMÓN Y CAJAL, S., «Habla el país: lo que dice el Dr. Cajal», El Liberal, 26 de octubre de 1898; RUBIO, F., «Habla el país: lo que dice el Dr. D. Federico Rubio», El Liberal, 8 de noviembre de 1898 .

22 «La enseñanza», La Ley, 21 de septiembre de 1898.

23 Ibid.

24 GÓMEZ Molleda (1981), pp. 424. 
cional Pedagógico de 1882, equiparar los sueldos de las maestras al de los maestros ${ }^{25}$; asimismo, había llevado a cabo una reforma muy oportuna de los estudios de Derecho, introduciendo en la carrera la Historia general del Derecho, el Derecho administrativo, la Hacienda pública y los Derechos internacionales público y privado. Pero, por otro lado, no conviene olvidar que Gamazo era consciente de que, si la tan anhelada reforma alcanzaba buen puerto, le serviría para potenciar enormemente su posición dentro del partido liberal con un Sagasta ya en la recta final de su dilatada carrera política y muy desprestigiado por la derrota ${ }^{26}$. No resulta sorprendente, por tanto, que Gamazo tomara sobre sus hombros gustosamente - por ambas razones: la afinidad ideológica y la ambición política - la tarea reformista y regeneradora de la enseñanza y empezara a producir rápidamente reales decretos.

Sin embargo, la excesiva premura, a resultas sobre todo de esas aspiraciones políticas, con la que llevó a cabo la reforma, y la corrupción imperante en la administración finisecular, a la que Gamazo - cacique al fin y al $\mathrm{cabo}^{27}$ - no supo ni quiso sustraerse, dieron rápidamente, como se verá a continuación, al traste con ella.

\footnotetext{
25 Puelles BeNíteZ (1980), p. 213.

26 «Situación política», Heraldo de Madrid, 22 de octubre de 1898.

27 El caciquismo fue una respuesta a la introducción del sufragio universal masculino en 1890, mediante el cual se pasó de los 850.000 electores de la década previa a los cinco millones posteriores a esta fecha. Cánovas fue de una aplastante sinceridad cuando, tras prever la imposibilidad de evitar el sufragio universal, manifestó de forma inequívoca la necesidad de falsificarlo permanentemente ante el riesgo de la desaparición de la propiedad y del capital. Y así se hizo. De tal manera que la continua manipulación permitió que, hasta la crisis final de 1923, todos los gobiernos que convocaron elecciones las ganaran por amplio margen. El mecanismo de fabricación de esos resultados electorales adecuados recibió el nombre de caciquismo. El sistema establecía, como ya señaló Costa en Oligarquía y caciquismo, una alianza entre la oligarquía política (formada por ministros, senadores, diputados, propietarios y directores de grandes periódicos, etc.) y la organización caciquil de los medios rurales (compuesta por terratenientes, propietarios de la tierra, aristócratas y burgueses adinerados), los cuales hacían de intermediarios o intérpretes de la exigencias urbanas, donde radicaban los centros de decisión política, al mundo rural, predominante en la sociedad de la época y con enormes tasas de analfabetismo. El enlace entre ambos se establecía por el intermedio de la figura del gobernador civil, quien ponía en marcha todo el aparato en el período electoral.

Sin embargo, como demostró Varela Ortega ya hace algún tiempo, el caciquismo respondió a necesidades funcionales de la sociedad de la Restauración y sus efectos no pueden valorarse como absolutamente negativos. El acuerdo entre las elites políticas para limitar la participación democrática y turnarse pacíficamente el poder desvaneció la amenaza de las intervenciones militares. Pero, además, el caciquismo, supuso también un avance en la organización política del país, al constituirse en una vía de superación de la concentración total del poder en las manos del ejecutivo. Hasta la consolidación del sistema caciquil, la mayoría de los parlamentarios eran, empleando la terminología taurina, cuneros a disposición del ministro de la Gobernación de turno, el cual los enchiqueraba a voluntad. Ante esta situación, el caciquismo representó un progreso por cuanto articuló la representación de intereses a través del legislativo y, con ello, se fueron desgajando competencias e independizando los poderes. Aunque, como es lógico, este funcionamiento mafioso de la administración llevó inevitablemente aparejados un alto coste de corrupción y prácticas clientelares. Cfr.: CosTA, J. (1998), Oligarquía y caciquismo como la forma
} 


\section{LOS DECRETOS DE GAMAZO}

La reforma gamacista, que partía de la premisa de no poder gravar el presupuesto dedicado a Instrucción Pública debido al calamitoso estado del Tesoro ${ }^{28}$, fue hecha a golpe de reales decretos ${ }^{29}$. Entre ellos, los cardinales fueron cinco: el real decreto de 13 de septiembre reformando la segunda enseñanza, el de 23 de septiembre reorganizando las Escuelas Normales, el de 30 de septiembre reformando la Facultad de Filosofía y Letras, y los dos de 11 de octubre incorporando, el primero, al Consejo de Instrucción Pública la Inspección General de Enseñanza (por el cual se reformaba también el citado Consejo) y estableciendo, el segundo, las reglas para los exámenes de ingreso en las Facultades ${ }^{30}$.

Todas estas normativas recogían recomendaciones del programa pedagógico de los institucionistas. El decreto sobre la reforma de la segunda enseñanza aumentaba en un año la duración del bachillerato, pasando de los cinco vigentes hasta entones (según el plan Groizard de 1894) a seis, e introducía una enseñanza teóricamente integral, complementando a este fin las enseñanzas culturales tradicionales con otras más técnicas y utilitarias. El decreto sobre las escuelas normales tenía como fin poner orden en la confusa situación en que malvivían muchas de ellas, intentando hacer extensivo a provincias algunas de las mejoras que se habían introducido ya en la escuela de Madrid, la cual funcionaba de una forma bastante aceptable ${ }^{31}$. El decreto de reforma de los estudios de Filosofía y Letras pretendía poner al día un plan de estudios que se había quedado muy obsoleto, incrementando de paso en dos años

actual de gobierno en España: urgencia y modo de cambiarla [1901-1902], ed. de J. Varela Ortega, Madrid, Biblioteca Nueva, pp. 63-106; VAREla ORTEGA, J. (1977), Los amigos políticos. Partidos, elecciones y caciquismo en la Restauración (1875-1900), Madrid, Alianza (para la redes de los políticos castellanos, como Germán Gamazo y Manuel Alonso Martínez, véase específicamente pp. 369385);VARELA ORTEGA, J. (1988), «La España política de fin de siglo», Revista de Occidente, n. ${ }^{\circ} 202$ 203, 43-77; pp. 72-74; y RoBles EgEA, A. (comp.) (1996), Política en penumbra. Patronazgo y clientelismo políticos en la España contemporánea, Madrid, Siglo XXI. Asimismo: ABELLÁN (1988), 22-24; Álvarez JunCo (1997), 56-59; DARDÉ (1997), 70-71; y PRo RuIZ, J. (1998), «La política en tiempos del Desastre», en: J. Pan-Montojo (coord.), Más se perdió en Cuba. España, 1898 y la crisis de fin de siglo, Madrid, Alianza, 151-260; pp. 173-191.

28 «Reformas en la enseñanza», La Época, 19 de septiembre de 1898.

$29 \mathrm{El}$ establecer reformas fundamentales mediante decretos no resultaba precisamente inhabitual en la administración, pero en este caso el proceder adquirió un carácter más «formalizado», pues el ministro recibió incluso una autorización expresa de las Cortes para poder reformar urgentemente la enseñanza mediante decretos. Y así lo empezó a hacer sin ninguna dilación «Dios queriendo y Gaceta habiendo», como se dijo en la prensa de aquellos días. Cfr.: MONTEMAR, F. de, «De Enseñanza», Heraldo de Madrid, 27 de septiembre de 1898 .

30 Todos estos decretos se encuentran reproducidos en: Anuario legislativo de Instrucción Pública correspondiente a 1898, Madrid, Joaquín Baquedano, 1899 (en lo sucesivo se citará como ALIP 1898), pp. 121-149; 152-191; 195-201; 220-239; y 239-247, respectivamente.

31 TURIN (1967), pp. 310-311. 
(pasaba de 3 a 5) su duración. El decreto que reformaba el Consejo de Instrucción Pública buscaba una revitalización de dicha institución, cuya función se había ido debilitando cada vez más a lo largo de la última década ${ }^{32}$. Y, por último, el decreto sobre el examen de ingreso en las facultades estaba dirigido a aumentar el prestigio de las universidades, a obtener una serie de garantías sobre el alumnado que accedía a las aulas universitarias y a facilitar ese maximum de alumnos por cátedra que habían reclamado los institucionistas en repetidas ocasiones.

Sin embargo, una lectura no meramente superficial de estas normativas sacaba a la luz numerosas deficiencias, debidas unas a la escasa meditación derivada de su veloz redacción y otras al sesgo interesado con el que fueron concebidas. Así, por ejemplo, el nuevo plan de bachillerato no incrementaba suficientemente su duración (Cossío recomendaba que se extendiera entre ocho y diez años), triplicaba innecesariamente los exámenes (cuando el sistema de exámenes era además uno de los puntos más criticados por los expertos en pedagogía) y, lo más grave, pretendía llevar a cabo la reforma sin modificar lo más mínimo los órganos auxiliares, técnicos y administrativos, lo cual condenaba al plan a ser uno más en una ya larga lista y a dejar pronto su lugar a otro nuevo realizado por el ministro de turno. La reforma de las normales era parcial, conservadora y de transición; no abordaba en absoluto los puntos cruciales para una verdadera renovación, como la reducción de su número (muchas de ellas completamente inútiles desde el punto de vista formativo y que debían su existencia a intereses localistas) y la creación de una Escuela Normal Superior de Magisterio, recomendada vehementemente en el Congreso Nacional Pedagógico del 92 y que no se fundaría hasta 1909. La revisión de Filosofía y Letras era, en la práctica, bastante modesta; y el aumento de tres a cinco años del nuevo plan se hacía en gran medida a costa de estirar asignaturas del antiguo, como fue el caso de la Metafísica. Las disposiciones para la reforma del Consejo de Instrucción Pública contenían flagrantes

32 Siguiendo el modelo de su homónimo francés, el Consejo de Instrucción Pública apareció en el Plan de 1836 en sustitución de la Dirección General de Estudios. La falta de acuerdo en lo referente a su composición hizo que se volviera a reorganizar la Dirección por R. D. de 1 de septiembre de 1838. Pero, finalmente, por R. D. de 1 de junio de 1843, se suprimió definitivamente la Dirección y se dividieron sus funciones entre tres organismos: una sección del Ministerio de la Gobernación, a la que competían las tareas ejecutivas; el Consejo de Instrucción Pública, al que se le otorgaba el carácter de un alto cuerpo consultivo; y una Junta de centralización de los fondos de Instrucción Pública, a la cual pasaban todas las atribuciones económicas en esta materia. La Gloriosa suprimió el Consejo en 1868, pero fue restituido con la restauración canovista del 74 y desde entonces y a lo largo de toda la década de los 80 tuvo amplias misiones en la inspección de la enseñanza, en el control de los libros de texto y de los programas, en la provisión de cátedras y en los traslados, creaciones y supresiones de establecimientos docentes. Pero en la década de los 90 su actividad fue decayendo progresivamente. Cfr.: ÁlvarEZ DE MoRALES, A. (1972), Génesis de la Universidad española comtemporánea, Madrid, Instituto de Estudios Administrativos, pp, 215-228; PESET y PESET (1992), pp. 39-40; y GóMEZ MOLLEDA (1981), pp. 456-457. 


\section{EL JORDÁN QUE HA DE PURIFICARNOS: LA REFORMA EDUCATIVA DE GERMÁN GAMAZO}

arbitrariedades ${ }^{33}$, algunas de las cuales dejaban, además, la puerta abierta para la práctica del clientelismo, al establecer que los consejeros, salvo los natos ( 3 de un total de 53), serían nombrados a propuesta del ministro de Fomento ${ }^{34}$. Y la normativa sobre el examen de ingreso en las facultades adolecía de un considerable confusionismo: era, por un lado, una duplicación del examen de grado, con el que coexistía hasta 1904, fecha en la que este último se suprimiría al llegar a la universidad la primera promoción del nuevo bachillerato ${ }^{35}$; y, por otro, aunque derogaba el carácter obligatorio de los cursos preparatorios de Derecho, Medicina y Farmacia (que se impartían, para las dos últimas carreras, en la Facultad de Ciencias), como había de transcurrir un año desde que se acababa el bachillerato antiguo (que constaba de 5 cursos y se terminaba con 16 años), hasta que acabara aquél (pues se exigía el tener los 17 cumplidos para poder matricularse en el examen de ingreso), los cursos preparatorios seguirían dándose para que los aspirantes a universitarios pudieran preparar con ellos dicho examen ${ }^{36}$.

Pero, además —y esto era quizás lo más grave—, la excesiva premura interesada de la reforma de Gamazo produjo no solo deficiencias y contradicciones puntuales, también condujo a que la supuesta renovación de la enseñanza se quedara en unos cuantos parches normativos sin ningún tipo de relación entre sí, dando al conjunto una imagen totalmente incoherente. Su magro resultado lo resumió Cossío en el informe sobre la reforma escolar presentado en la Asamblea Nacional de Productores de Zaragoza, en febrero de 1899, con las siguientes palabras: «Qué se ha hecho, al cabo, en este año terrible? Unas cuantas reformas de pormenor, cambios de nombre, provisiones de vacantes, aumento o disminución de exámenes, asignatura o año más o menos. Todo como si estuviéramos en el mejor de los mundos pedagógicos, y como si no fueran los principios mismos y las bases lo que hay que remover» ${ }^{37}$.

\section{LA NECESIDAD DE ESPERANZA Y LA FAVORABLE ACOGIDA DE LAS MEDIDAS}

En un primer momento, la opinión pública, ofuscada por el ansia de cambios educativos a todo trance, apenas percibió alguno de esos desatinos. Así, una vez publicados los primeros decretos, la mayoría de la prensa mostró una reacción muy propi-

33 Los funcionarios de la secretaría, por ejemplo, no podían ser destituidos una vez nombrados por el ministro; sólo cuando estos cesaran, los puestos serían cubiertos por oposición. ALIP 1898, p. 225.

34 ALIP 1898, p. 224.

35 ALIP 1898, p. 247.

36 ALIP 1898, pp. 246-247.

37 El texto íntegro del informe se publicó posteriormente, bajo el título de «La reforma escolar», en el número del 31 de octubre de 1899 de la Revista Nacional, pp.321-323. Fue publicado posteriormente en Cossío (1929), pp. 230-243. Se encuentra también reproducido en: Historia de la educación en Espa$\tilde{n} a$, tomo III, 1982, 338-351. La cita corresponde a la p. 350. de esta última obra. 
cia $^{38}$. En el grupo de los periódicos de empresa, el Heraldo de Madrid señaló su creencia en que, al menos en la intención, «el Sr. Gamazo va sinceramente a la reforma de la enseñanza» ${ }^{39}$. El Imparcial, en un artículo que coronaba reclamando un aplauso para el nuevo plan de la segunda enseñanza, porque «en su totalidad el plan responde a una grande y muy sentida necesidad de la nación», resaltó su «segura base, siquiera tenga tales o cuales defectos de detalle ${ }^{40}$, y solicitó en otro publicado más adelante, a raíz de la reforma de los estudios de Filosofía y Letras, el apoyo para su persona «por dar mayor amplitud y fuerza a la enseñanza en medio de la indiferencia universal» ${ }^{41}$. Tan sólo El Liberal puso la nota discordante en este grupo, tachando la reforma del bachillerato de «absurda» e «incongruente» y recomendando «anularla, deshacerla de la cruz a la fecha, porque se ha procedido con tal atolondramiento en su confección que no sólo la exposición del decreto esta plagada de contradicciones con el articulado del mismo, sino que en la exposición (...) hay conceptos que se desvirtúan y rectifican unos a otros $»^{42}$. Abundando en esta línea crítica, aparecieron aquí a continuación cinco trabajos recopilando los numerosos desatinos del plan, hecho «sin tener en cuenta los que le preceden y los que le siguen, sin reformar al mismo tiempo los órganos auxiliares, técnicos y administrativos, y sin causar aumento de gastos» ${ }^{43}$.

Entre los periódicos de partido los beneplácitos fueron también predominantes. En el ala liberal, El Correo, el órgano de Sagasta, enfatizó, en uno de los primeros artículos dedicados a las reformas, el «criterio racional y científico, a la vez que esencialmente práctico» que animaba el plan de estudios de secundaria ${ }^{44}$. Pocos días más tarde, calificaba de «gran adelanto en el problema de la enseñanza» esta disposición ministerial ${ }^{45}$. Y, a últimos de mes, un trabajo de Becerro de Bengoa se remataba con estas elogiosas palabras: «con pocos recursos, dada la magnitud de la obra, y con otras deficiencias, pero con esa voluntad decisiva y con labor incansable de parte de todos, ha de intentarse marchar adelante y marchar bien en la segunda enseñanza.

38 Sobre los diferentes tipos de prensa, su público y la relación entre prensa y opinión pública en la

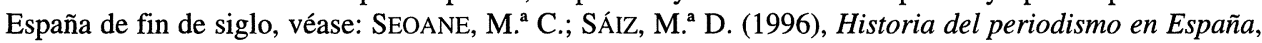
tomo III [El siglo XX: 1898-1936], Madrid, Alianza, pp.23-34.

39 «De enseñanza», Heraldo de Madrid, 21 de septiembre de 1898.

40 «Reorganización de la segunda enseñanza», El Imparcial, 15 de septiembre de 1898.

41 «Las reformas de la enseñanza», El Imparcial, 3 de octubre de 1898.

42 «El plan de Gamazo», El Liberal, 16 de septiembre de 1898.

43 La cita es de: J. de C. P., «La reforma de la enseñanza. Tejer y destejer I», El Liberal, 27 de septiembre de 1898. Los otros artículos a los que se hace mención en el texto, firmados también con las mismas iniciales, fueron: «Reforma de la segunda enseñanza. Plan de estudios II», El Liberal, 29 de septiembre de 1898; «Reformas de la segunda enseñanza. El personal docente III», El Liberal, 30 de septiembre de 1898; «Reformas de la segunda enseñanza. Programas y libros de texto IV», El Liberal, 3 de octubre de 1898. «Reformas de la segunda enseñanza. Los exámenes V», El Liberal, 4 de octubre de 1898.

44 «Segunda enseñanza», El Correo, 14 de septiembre de 1898.

45 «La segunda enseñanza: el decreto de Sr. Gamazo», El Correo, 17 de septiembre de 1898. 


\section{EL JORDÁN QUE HA DE PURIFICARNOS: LA REFORMA EDUCATIVA DE GERMÁN GAMAZO}

Para ello ha señalado el itinerario, con verdadero acierto, el Sr. Gamazo, dignamente secundado por persona tan perita en materias de enseñanza como el Director general Sr. Santamaría de Paredes» ${ }^{46}$. El Globo, propiedad del conde de Romanones, repitió el día 15, sin ningún pudor, el párrafo final del comentario aparecido en El Correo el día anterior sobre el criterio racional, científico y práctico de las medidas ${ }^{47}$; y en los artículos posteriores que fueron apareciendo sobre las reformas y los problemas pedagógicos aprovechó para llamar la atención sobre la «beneficiosa obra del Sr. Gamazo» ${ }^{48}$ y su «entusiasmo con todo lo que a la enseñanza se refiere» ${ }^{49}$.

En el ala conservadora de la prensa partidista, el silvelista El Tiempo no se mostró precisamente como un devoto partidario de la reforma gamacista de la secundaria, pero tampoco llegó a condenarla: «el nuevo plan (...) no merece, en nuestro concepto, ni plácemes entusiastas ni censuras acerbas. Es una obra modesta, ordenada, práctica, que mejora lo presente, sin satisfacer» ${ }^{50}$, y dedicó a continuación una serie de artículos a su análisis pormenorizado, sopesando sus ventajas e inconvenientes ${ }^{51}$. Más adelante consideró que el decreto sobre la reforma de las Escuelas Normales era, no obstante su excesiva timidez, «un intento progresivo, generoso y loable» en el que «se reconoce la buena doctrina» 52 y, como había hecho con la anterior disposición, examinó también este decreto en tres pormenorizados trabajos ulteriores ${ }^{53}$. El Nacional de Romero Robledo tampoco mantuvo una postura tan fervorosa como las de $E l$ Correo o El Globo; manifestó prontamente ante las reformas iniciales que la «primera impresión es buena, pues basta saber que el Sr. Gamazo tiende a hacer menos cómoda, más laboriosa la segunda enseñanza, para que nos parezca digo de un entusiástico aplauso» ${ }^{54}$, pero luego adoptó una posición más distante: «no nos parecen tan excelentes como él se ha imaginado, ni tan despreciables como han dado en sostener los detractores sistemáticos de toda innovación» ${ }^{55}$. De todos los medios conservadores, fue sin duda La Época el que, al menos en un principio, más halagüeño se mos-

\footnotetext{
46 BECERRO DE BENGOA, R., «La reforma de la segunda enseñanza», El Correo, 25 de septiembre de 1898

47 «Reformas en la enseñanza», El Globo, 15 de septiembre de 1898. Cfr. el artículo citado en la nota 44 .

48 «Escuelas y maestros. La reforma de Gamazo». El Globo, 17 de septiembre de 1898.

49 «Escuelas y maestros», El Globo, 9 de octubre de 1898.

50 «Estudios de segunda enseñanza», El Tiempo, 17 de septiembre de 1898.

51 «Estudios de segunda enseñanza II», El Tiempo, 18 de septiembre de 1898; «Estudios de segunda enseñanza III», El Tiempo, 20 de septiembre de 1898; «Estudios de segunda enseñanza IV», El Tiempo, 21 de septiembre de 1898; «Estudios de segunda enseñanza, V», El Tiempo, 23 de septiembre de 1898; y «Estudios sobre segunda enseñanza VI», El Tiempo, 24 de septiembre de 1898.

52 «Escuelas Normales», El Tiempo, 2 de octubre de 1898.

53 «Las Escuelas Normales II», El Tiempo, 5 de octubre de 1898; «Las escuelas Normales III», El Tiempo, 8 de octubre de 1898; y «Las Escuelas Normales IV», El Tiempo, 11 de octubre de 1898.

54 «Obra necesaria», El Nacional, 14 de septiembre de 1898.

55 «La segunda enseñanza», El Nacional, 8 de octubre de 1898. 
tró con Gamazo, pues al pasar revista al decreto del 13 de septiembre hizo constar que «ecléctico en su espíritu, de carácter práctico (...), mejora sin duda lo actual» ${ }^{56} \mathrm{y}$ que con él se tenía el propósito de «dotar a España de un plan de enseñanza en armonía con el estado de cultura general de todos los países civilizados» $\mathrm{y}$ «de comunicar seriedad a los estudios, de aumentar el rigor de los tribunales, de ampliar los conocimientos de la segunda enseñanza, de corregir abusos» ${ }^{57}$.

La prensa médica y farmacéutica, que importa considerar para valorar la recepción que tuvo el examen de ingreso en las Facultades, se mostró también mayoritariamente a favor de la reforma gamacista. El Siglo Médico consideró muy positivamente el examen de ingreso como un medio para acabar con el exceso de médicos, ya que «de esta suerte ingresarán en las Escuelas de Medicina los más aptos y en el número que las necesidades lo exijan, y será éste el medio de acabar muy pronto con el exceso de personal, causa de no pocas desdichas» ${ }^{58}$. La Farmacia Española alabó también este decreto «hace mucho tiempo propuesto por personas muy peritas en achaques de enseñanza universitaria» ${ }^{59}$. La Correspondencia Médica, por el contrario, mostró un radical rechazo a las reformas dispuestas por «el gran cacique Gamazo», recordando de paso que fue este ministro quien «influyó poderosamente para que en Valladolid sigan funcionando con todo desahogo las empresas médicofarmacéuticas, llamadas sociedades benéficas» ${ }^{60}$.

\section{EL RÁPIDO FIASCO DE LAS DISPOSICIONES}

Pero la ilusión por la bondad de las reformas duró apenas un mes. A partir de la primera semana de octubre, las críticas contra Gamazo, hasta entonces puntuales, se generalizaron y arreciaron. A El Liberal, que no desaprovechó ningún pretexto para proseguir su campaña en detrimento de $\mathrm{Gamazo}^{61}$, se le unió el Heraldo que denunció, con motivo de la modificación de los estudios de Filosofía y Letras, la carencia de sentido de los decretos del «jacobino mal traducido» que, «como un «Maximiliano Robespierre, no reconoce los hechos anteriores, y tiende a organizarlo todo según su propia visión y su propia idea», augurando que «mañana la emprenderá el Sr.

56 «a reconstitución del país», cit. en nota 7.

57 «El mejor camino», La Época, 15 de septiembre de 1898.

58 «Un Real Decreto plausible», El Siglo Médico, 16 de octubre de 1898, p. 657.

59 «La enseñanza pública», La Farmacia Española, 20 de octubre de 1898, 664-665; p. 665.

60 «Reformas en la enseñanza», La Correspondencia Médica, 24 de septiembre de 1898, pp. 280-281.

61 En estos primeros días de octubre aparecieron aquí dos artículos en donde se criticaba a Gamazo, uno con motivo de la opinión negativa de algunos catedráticos de la Facultad de Ciencias de la Central sobre su proyectada reforma: «Los catedráticos de ciencias y el Sr. Gamazo», El Liberal, 6 de octubre de 1898; y otro sobre la necesidad de la exigencia de títulos pedagógicos para las religiosas que se dedican a la enseñanza: «La educación de la mujer», El Liberal, 9 de octubre de 1898. 
Gamazo con la Facultad de Derecho, al otro con la del Notariado, al otro con Ciencias, con Medicina, con Farmacia, hasta que llegue el turno a las matronas. ¿Y a la postre, qué? A la postre un poco de papel emborronado y algunos amigos servidos con prebendas universitarias» ${ }^{62}$. Un poco más tarde, $L a$ Época, que ya había lanzado las primeras andanadas contra los planes del ministro por ser más «remiendo que construcción» ${ }^{63}$ y por no fomentar «el espíritu práctico que habría de dar utilidad a esos estudios» ${ }^{64}$, advertía de la inutilidad de la reforma del Consejo de Instrucción Pública, que «gana poco con la actual reforma y seguirá dejando mucho que desear», pues «descúbrese en la inamovilidad decretada en ocasión en que el personal de consejeros es muy desigual, algo y un mucho de espíritu de partido» ${ }^{65}$. Y, posteriormente, El Imparcial, se unía al coro de los detractores, denunciando que «en los últimos decretos los errores aumentan y llegan a ser inexplicables», en especial en el dedicado al examen de ingreso en la Universidad, una prueba que, «sin añadir nueva ciencia, se limita a pedir mayores pruebas de lo ya aprendido» y que para colmo de males incluía el absurdo de obligar a traducir el alemán ${ }^{66}$, cuando «en ninguno de los institutos de España se enseña el alemán, si no es en los de Barcelona y en el San Isidro de Madrid (donde, por cierto, está la cátedra vacante)»; «ipor qué se exige el alemán y no el inglés $\rightarrow$ se preguntaba el autor al final del artículo - cuando en los institutos españoles hay muchos catedráticos de inglés?» ${ }^{67}$.

Estas censuras pusieron cada vez más en entredicho que la reforma gamacista estuviera orientada a la revitalización de la nación y evidenciaron que su premura, con los consiguientes errores e incoherencias que acarreaba, obedecía más a razones per-

62 «Un reformador», Heraldo de Madrid, 2 de octubre de 1898.

63 «Reformas en la enseñanza», La Época, 19 de septiembre de 1898.

64 MARQUÉS DE PERALEJA, «Otro plan de enseñanza», La Época, 24 de septiembre de 1898.

65 «Más reformas en la Instrucción Pública», La Época, 13 de octubre de 1898.

66 La prueba constaba de dos ejercicios, uno común para todos los estudiantes y otro específico de cada facultad. El común consistía en la traducción por escrito y con diccionario de tres breves textos, uno de latín, otro de francés y otro de alemán, así como en el análisis gramatical de la primera línea de cada texto. Aprobado este primer ejercicio, se pasaba al específico, que tenía dos partes: una oral y otra escrita. En la parte oral se debía contestar una pregunta de cada una de las asignaturas del grupo de cada Facultad. En el caso de Medicina y Farmacia, estas asignaturas eran: Física, Química, Zoología, Botánica y Mineralogía (las materias del hasta entonces curso preparatorio); la parte escrita comprendía el desarrollo de un tema, a elección del tribunal, correspondiente a una de las asignaturas de ese grupo de cada facultad. ALIP 1898, pp. 245-246.

67 «Las reformas en la enseñanza: el ingreso en las Facultades». El Imparcial, 21 de octubre de 1898. Con todo, las opiniones sobre el examen de ingreso en las Facultades estuvieron muy divididas. La Época se mostró, incluida la espinosa cuestión del alemán, abiertamente a su favor: «En el decreto suprimiendo el año preparatorio, que no tenía un solo defensor, encontramos plausible el que se pida como obligatorio el idioma alemán y el ejercicio práctico, aumentado al oral; así como el límite a los diez y siete años para el ingreso en los estudios universitarios». «Más reformas en la Instrucción Pública», cit. en nota 65. Asimismo, recuérdese la positiva actitud ante el mismo mantenida por El Siglo Médico (véase la nota 58). 


\section{ÁNGEL GONZÁLEZ DE PABLO}

sonales de promoción política que a los intereses del país. La posición de Gamazo empeoró todavía más a partir de la tercera semana de octubre, en donde comenzaron a salir a la luz una serie de denuncias en torno a las corruptelas que acompañaban a la reforma supuestamente regenadora. La primera fue la revelada por El Nacional en relación con que el preámbulo del decreto sobre la reforma de la enseñanza secundaria coincidía casi ad litteram con el prólogo de la obra Gramática razonada histórico-crítica de la lengua francesa, libro de texto del catedrático de francés en el madrileño Instituto del Cardenal Cisneros, Fernando Araujo y Gómez ${ }^{68}$. El Heraldo echó leña al fuego al publicar en portada al día siguiente, uno debajo del otro, algunos párrafos - prácticamente idénticos-del preámbulo del decreto y del prólogo de la obra de Araujo ${ }^{69}$. El mismo Araujo se defendió en las páginas de El Globo, haciendo notar que el ministro había hecho «multitud de retoques» personales a su trabajo y que además éste había afirmado públicamente que no tenía «la pretensión de ser el redactor material de todo lo que firmase» ${ }^{70}$. Pero la impresión de que la tan cacareada reforma renovadora ni siquiera era nueva, sino más bien un refrito de anteriores trabajos, quedó ya indeleble.

La segunda, relacionada con la anterior, consistió en la divulgación de los favoritismos (o polacadas, como se los llamaba entonces) con los que las disposiciones iban de consuno ${ }^{71}$. Así, el real decreto de reforma del Consejo de Instrucción Pública, como se señaló más arriba, facilitaba la práctica del amiguismo de forma descarada al otorgar al ministro la facultad del nombramiento directo de los consejeros, lo que conllevaba la anulación del sistema electivo entre las diversas corporaciones y entidades docentes que se había seguido hasta entonces ${ }^{72}$. El mecanismo anterior era muy imperfecto, pero el nuevo fue todavía peor, pues, como la prensa no tardó en apuntar, de los trece consejeros nombrados en una promoción, once eran «muy dignos y muy cultos, pero con una significación ministerial bien notoria» ${ }^{73}$. Sin embargo, la polacada con más resonancia fue la llamada araujada, que surgió también de la normativa que reformaba el Consejo de Instrucción Pública. En este decreto, Gamazo instituyó dos nuevos puestos de Inspector general de Instrucción Pública, pasando así de los dos que había habido tradicionalmente a un total de cuatro. Los emolumentos con los que el cargo estaba dotado eran cuantiosos, pues ascendían a 10.000 pesetas anuales ${ }^{74}$, a las que había que añadir, según algunas estimaciones,

68 «Justicia gamacista: inspectores de Polonia», El Nacional, 17 de octubre de 1898.

69 «Reformadores», Heraldo de Madrid, 18 de octubre de 1898.

70 ARAUJO, F., «En defensa propia: un descubrimiento prodigioso», El Globo, 20 de octubre de 1898.

71 Recuérdese lo expuesto en la nota 27.

72 Véase la nota 33.

73 «Amistosamente», Heraldo de Madrid, 19 de octubre de 1898

74 ALIP 1898, p. 226. 


\section{EL JORDÁN QUE HA DE PURIFICARNOS: LA REFORMA EDUCATIVA DE GERMÁN GAMAZO}

unas 5.000 por dietas ${ }^{75}$. Pues bien, una de estas sinecuras, concedidas directamente por el ministro, recayó sobre la persona de Fernando Araujo (a la que no adornaban excesivos méritos profesionales), posiblemente como recompensa por esos servicios prestados como autor o coautor de las reformas ${ }^{76}$. El escándalo resultaba todavía más sangrante si se tiene en cuenta que simultáneamente se publicaba que la enseñanza primaria tenía una deuda de ocho millones ${ }^{77}$, que el sueldo de los maestros de primaria (cobrado irregularmente) era inferior al de un peón, pues oscilaba entre las 145220 pts. al año para los más bajos y las $625-825$ pts. anuales para los más altos ${ }^{78}$, y que no había dinero para abonar las pagas devengadas a los repatriados ${ }^{79}$.

Así las cosas, a finales de la tercera semana de octubre, la imagen pública de Gamazo y su reforma, debido a la alocada celeridad (cada vez más incuestionablemente denostada como interesada) y a las corruptelas que la rodeaban (cuando supuestamente debía haber sido una de las medidas más eficaces para acabar con ellas en tanto generadora de la anhelada regeneración), estaba irremisiblemente deteriorada. Pero la gota que colmó finalmente el vaso fueron las salpicaduras del caso Ribot. Este escándalo estalló cuando el director de El Nacional, Adolfo Suárez de Figueroa, que había vertido en este periódico una serie de acusaciones contra Pascual Ribot ${ }^{80}$, gobernador de Cádiz y pariente y protegido de Gamazo, fue encarcelado, por voluntad expresa de un iracundo Gamazo y pese a gozar de inmunidad parlamentaria, en la madrugada del día 21. La causa fue no haber sometido a la censura previa una Hoja Nacional Extraordinaria, editada el 20 por Figueroa a raíz de la censura a que fue sometida su contestación a una carta que Ribot había mandado a El Nacional proclamando su inocencia. Los periódicos del 21 pidieron unánimemente, con comentarios durísimos, la caída del ministro y la libertad del periodista y diputado ${ }^{81}$. Ante la

\footnotetext{
75. «Seriedad», Heraldo de Madrid, 18 de octubre de 1898.

76 «La Araujada», El Nacional, 19 de octubre de 1898.

77 «La enseñanza primaria. Deuda atrasada: ocho millones», El Liberal, 15 de octubre de 1898; «Más vergüenzas», El Tiempo, 18 de octubre de 1898.

78 «La enseñanza». La Ley, 21 de octubre de 1898; DELGADO CRIADO (1977), p. 18; y TURIN (1967), p. 91

79 «La obra de Gamazo», El Liberal, 19 de octubre de 1898.

80 El Nacional acusó a Ribot de tener arrendado el juego (que era ilegal) en la provincia por 4.000 pts. anuales y de someter a reconocimiento y pago de cartilla sanitaria, a razón de cinco pesetas mensuales, a los homosexuales que ejercían la prostitución. «El reino de sarasa», El Nacional, 17 de octubre de 1898 .

81 «Representaba el espíritu reflexivo, y revélase en la Gaceta con premuras de jacobino; mostrábase orgulloso de sus opiniones, y al través de sus decretos denúnciase la falsilla de un familiar; pretendíase de mesurado y reparón en los gastos públicos, y altera toda la legislación de enseñanza para dar ocupación bien retribuída a sus modestos colaboradores; era el hombre justo, el hombre de ley, y justicia y legalidad caen debajo de sus personales pasiones; (...) era el hombre de Estado frío y sereno, fuerte y seguro, con que España había de regenerarse, y en un día de ira produce una inmensa perturbación (...) La caída del Sr. Gamazo parécenos inevitable. La libertad del Sr. Figueroa también. Son desagravios que España se debe a sí misma». «Ceguedad». Heraldo de Madrid, 21 de octubre de 1898.
} 


\section{ÁNGEL GONZÁLEZ DE PABLO}

presión generalizada de la prensa, Figueroa fue liberado el mismo 22 y ese día dimitieron Ribot y Gamazo, tomando éste — según los medios de prensa- una decisión visceral llevado por su susceptibilidad herida ${ }^{82}$.

Sagasta pasó a encargarse interinamente del ministerio de Fomento ${ }^{83}$, tras aceptar con agrado apenas disimulado la dimisión de su ministro, el cual había llegado a convertirse en aquellos dos últimos meses en un manifiesto rival. Gamazo salía además bastante mal parado del trance, distanciado como estaba de sus facciones liberales más afines - los monteristas - desde su entrada en el gobierno en mayo y con su prestigio muy menoscabado por los recientes escándalos. El ya ex-ministro, enemistado abiertamente con Sagasta, no tardó en escindirse del Partido Liberal ${ }^{84}$. No resulta precisamente asombroso que una de sus primeras iniciativas en esa nueva etapa, habida cuenta de las experiencias con los contundentes efectos de las campañas de la prensa (que había pasado de apoyarle a atacarle en tan breve plazo), fuera la de fundar un nuevo periódico, El Español ${ }^{85}$, cuyo primer número aparecería el 15 de diciembre.

\section{LA DESAPARICIÓN DE LA REFORMA GAMACISTA}

Tras su dimisión, tan sólo El Globo siguió defendiendo las reformas de Gamazo, instando a Sagasta no sólo a mantenerlas sino a continuarlas por el mismo camino «sin vacilaciones, sin miedo a las responsabilidades» ${ }^{86}$. Pero la mayoría de la prensa abogó por su pronta derogación. El medio más voluntarioso en este sentido, dada su marcada animadversión para con Gamazo, fue El Liberal, que se constituyó a este fin en portavoz de las protestas de las revistas políticas ${ }^{87}$, del resto de periódicos ${ }^{88}$, de los padres, profesores y directores de colegios $^{89}$, de los miembros del Consejo de Instrucción Pública ${ }^{90}$ y de las revistas de educación ${ }^{91}$. Las revistas de los medios profesionales no tardaron en suscribir esta exigencia, bien - como la jurídica La Leydeplorando el caciquismo de que había hecho gala ${ }^{92}$, bien —como La Corresponden-

\footnotetext{
82 «La dimisión de Gamazo», El Liberal, 22 de octubre de 1898.

83 «Sagasta, ministro de Fomento», El Liberal, 23 de octubre de 1898.

84 «Crisis inevitable», El Imparcial, 1 de noviembre de 1898.

85 Su sede fue uno de los principales puntos de encuentro de los senadores y diputados afines a Gamazo. «Los gamacistas», El Imparcial, 1 de noviembre de 1898.

86 «Adelante», El Globo, 26 de octubre de 1898.

87 «La reforma de la enseñanza: otro voto en contra», El Liberal, 25 de octubre de 1898

88 «La reforma de la enseñanza», El Liberal, 26 de octubre de 1898.

89 «La reforma en la enseñanza: no puede seguir»,. El Liberal, 29 de octubre de 1898.

90 «Los decretos de Gamazo», El Liberal, 29 de octubre de 1898.

91 «Las reformas de Gamazo», El Liberal, 1 de noviembre de 1898.

92 «iFuera jerarcas bastardos!», La Ley, 30 de octubre de 1898.
} 
cia Médica - mostrando su alivio porque apenas había dejado impronta «su fatal influencia sobre los estudios de nuestra carrera» ${ }^{93}$.

Huelga casi decir, a tenor de lo anterior, que la vigencia de los decretos de Gamazo fue en extremo fugaz. Su R. D. de reforma de la enseñanza secundaria quedó sustituido por el de Pidal de 26 de mayo de 1899; el R. D. de reorganización de las Escuelas Normales fue reemplazado por el de García Alix de 6 de julio de 1900; el R. D. de reforma de la Facultad de Filosofía y letras dejó paso al de García Alix de 20 de julio de 1900; el R. D. de reforma del Consejo de Instrucción Pública fue invalidado por el de García Alix de 18 de mayo de 1900; y el R. D. de exámenes de ingreso en las facultades quedó derogado por Pidal el 29 de abril de 1899 sin haberse llevado a cabo (posteriormente García Alix sacaría una nueva disposición sobre este examen de ingreso, la cual sí llegó a efectuarse).

De todas formas, el descalabro de la iniciativa gamacista permitió extraer dos conclusiones de las que se tomó buena cuenta entre los reformadores. La primera consistió en la necesidad de situar a partir de entonces las reformas educativas dentro de un programa de profundas reformas sociales, políticas y económicas, a fin de que las corruptelas inherentes al funcionamiento del sistema no acabaran desvirtuando, como había pasado con Gamazo, los propósitos docentes renovadores. Esta idea se puso sobre el tapete en los medios periodísticos a los pocos días de la dimisión del ministro de Fomento. A modo de ejemplo, una editorial de El Liberal, empleando las metáforas médicas tan al uso en estos momentos, afirmaba que «antes de buscar la medicina y para que ésta produzca su benéfica acción, importa desinfectar la casa y purificar el ambiente», pues en el fiasco gamacista «se contiene una lección que aprovechará a los cándidos y desengañará a los indecisos. Enseña y prueba que mientras duren la organización, el mecanismo y los procedimientos que se hallan en vigor, serán todos los sacrificios estériles y todos los esfuerzos inútiles» ${ }^{94}$. Siguiendo esta linea, las principales obras de carácter regeneracionista aparecidas en los años inmediatamente posteriores, como las de Picavea, Morote y Costa ${ }^{95}$, contemplarán las reformas educativas siempre dentro de un conjunto más amplio de cambios de variada índole. Un proceder similar seguirán, asimismo, los movimientos del regeneracionismo político en sus comunicados más significativos. Así, en el manifiesto de la Liga Nacional de Productores, liderada por Costa y surgida de la reunión en Zaragoza de las cámaras y organizaciones agrarias en febrero de 1899, los apartados dedicados a la reforma de la educación y la ciencia (el 35, 36, 37 y 38, elaborados bási-

93 «Gamazo en tierra», La Correspondencia Médica, 30 de octubre de 1898, p. 319.

94 «Lo que se deduce», El Liberal, 23 de octubre de 1898.

95 Cfr.: MaCías PICAVEA, R. (1996), El problema nacional [1899], ed. de A. de Blas Otero, Madrid, Biblioteca Nueva, pp.243-313; MOROTE, 1. (1997), La moral de la derrota [1900], ed. de J. S. Pérez Garzón, Madrid, Biblioteca Nueva, pp. 193-262; y CosTA (1898 [1901-1902]), pp. 107-132.. 


\section{ÁNGEL GONZÁLEZ DE PABLO}

camente a partir del informe de Cossío presentado ante la asamblea) ${ }^{96}$ están incluidos dentro de un total de 85 que recopilan, junto a las educacionales, una serie de propuestas renovadoras en los apartados de agricultura, caminos y carreteras, transportes y comercio exterior, crédito agrícola, reformas sociales, clases pasivas, ingresos del Estado, gastos especiales, gastos generales y deuda pública, Banco de España, administración pública y ejército ${ }^{97}$.

La segunda radicó en la exigencia de dotar las disposiciones de reforma educativa de una coherencia de conjunto, para que tuvieran, escarmentando en lo ocurrido con las de Gamazo, una aplicabilidad duradera. Los primeros intentos serios de dar carta de naturaleza a esta exigencia correspondieron a García Alix y a Romanones, que fueron también los primeros ministros de Instrucción Pública. Ambos se inspiraron a tal fin en ese texto de Cossío ya mencionado sobre la reforma escolar, presentado en la reunión ante la Asamblea Nacional de Productores de Zaragoza, como programa para establecer las distintas disposiciones legales que fueron emitiendo entre $1900 \mathrm{y}$ $1902^{98}$. Hay que tener en cuenta que ni García Alix (por su oportunismo político y por su desbocado apresuramiento) ni Romanones (por su diversas actividades caciquiles) ${ }^{99}$ escaparon a esas coordenadas propias de la política de la Restauración, tan evidentes, como vimos, en Gamazo. Además, aunque unas pocas perduraron, la mayoría de sus disposiciones se perdieron en la tumultuosa corriente de los sucesivos ministerios. Pero, a pesar de todo, con ellos se pusieron, mal que bien, las bases para el arraigo legislativo del institucionismo, lo que posibilitó algunos de los más valiosos frutos educativos de las tres décadas siguientes.

\footnotetext{
96 Véase la nota 37.

97 «Manifiesto de la Liga Nacional de Productores», Heraldo de Madrid, 13 de abril de 1899.

98 TURIN (1967), p. 251

99 Cfr.: MORENO LuZÓN, J. (1996), El conde de Romanones. Caciquismo y política de clientelas en la España de la Restauración, Madrid, tesis doctoral inédita, UCM; y MORENO LUZÓN, J. (1998), Romanones. Caciquismo y política liberal, Madrid, Alianza.
} 